\title{
GROSS ANATOMICAL FEATURES AND OSTEOMETRIC VARIABLES OF THE SCAPULA OF THE AFRICAN TREE SQUIRREL (FUNISCIURUS ANERYTHRUS), HOUSE (RATTUS RATTUS) AND WISTAR RATS
}

\author{
Ekeolu Oyetunde Kazeem ${ }^{1} .$, Omirinde Jamiu Oyewole $^{2 *}$ and Usende Levi Ifukot ${ }^{3}$ \\ ${ }^{1}$ Department of Veterinary Anatomy, Faculty of Veterinary Medicine, University of Benin, Benin City, \\ Nigeria P.M.B. 1154. \\ ${ }^{2}$ Department of Veterinary Anatomy, Faculty of Veterinary Medicine, University of Jos, Jos, Nigeria \\ P.M.B 2084. \\ ${ }^{3}$ Department of Veterinary Anatomy, Faculty of Veterinary Medicine, University of Abuja, Abuja, Nigeria \\ P.M.B 117. \\ ${ }^{*}$ Corresponding author e-mail address: omirindejamiu@yahoo.com/ +2348069735125
}

\begin{abstract}
This study comparatively investigated gross features and osteometric variables in scapula of three rodents: tree squirrel (Funisciurus anerythrus), house (Rattus Rattus) and Wistar rats. A total of thirty three animals (11 per rodent species) were used for the study. The rodents were anaesthetized using ketamine and xylazine combination ( $80 \mathrm{mg} / \mathrm{kg}: 10 \mathrm{mg} / \mathrm{kg}$ body weight), sacrificed and processed for scapular bone extraction by burying method. Grossly, the scapular bones are flattened in all the rodents and have various shapes; semicircular in squirrel and roughly triangular in both Rattus rattus and Wistar rats. The scapula of the squirrel bears a hook-like acromion process and a distinct subscapular spine. Osteometric variables; scapular width and length of scapular neck are significantly reduced $(p<0.05)$ in the squirrel relative to other rodents. While the length of glenoid and diameter of infra spinatous fossa in Rattus rattus as well as the scapular spine length in squirrel respectively show marked increase when compared to other rodents.
\end{abstract}

Keywords: Funisciurus anerythrus, Rattus rattus, Wistar, scapula, morphology, osteometry, comparative

\section{INTRODUCTION}

The scapula is a flat bone that lies on the cranio-dorsal part of the thorax (Dyce et al., 2002), and held in place with the thorax by an arrangement of muscles, called a syssarcosis (Valasek et al., 2010). The general scapula shape in mammalian species is triangular (Dyce et al., 2002), and the morpho-physiological role is for accommodation and attachment of the series of muscle that helps to hold the weight of the trunk in place (Preuschoft et al., 2010; Nyakatura and Fischer, 2011; Kawashima et al., 2015).
In different species of mammals, there are modifications in the anatomy of their scapulae as a means of survival in their various environments (Kawashima et al., 2015). One of such modifications as seen in some mammals, is the extension of the scapula by its cartilage which ossifies with age, increasing the surface area for muscular attachment, and the flatness of the scapula bearing scapular spine and acromial processes (Dyce et al., 2002; Rupert et al., 2014), the shape of scapula of terrestrial and highly arboreal mammals is closely related to the locomotory functions of the shoulder (Young, 2006). 
Rattus rattus, commonly called house or black rat, belongs to the family Muridae, sub-family Murinae and genus Rattus. Rattus rattus has round, dark eyes (Innes, 2005a), distinguishly long ears and tail (Innes, 2005a; Shiels, 2010; Shiels et al., 2014). It is well known to damage crops, stored foods and kill native species, and serves as a vector for human diseases (Shiels et al., 2014).

Wistar rat, an outbred albino rat, is one of the most popularly used rats for laboratory research. It was first developed at the Wistar Institute in 1906 to serve as model organism for biological and medical research. Grossly, the rat is characterized by wide head, small and thick ears, and a tail length that is about $85 \%$ of its body length. The tail varies with the sex being slightly longer in the females than in males (Greene, 1968).
Funisciurus anaerythrus, commonly called rope squirrels, is a mammal of the order Rodentia that belongs to the family Sciuridae (Hoffman et al., 1985; Thorington and Darrow, 2000). The latter is made up of 50 genera and 273 species. $F$. anaerythrus belongs to the genus Funisciurus (Thorington and Darrow, 2000; Thorington et al., 1997). This species of squirrel is predominantly found in the rainforest of West African region where it is hunted for meat.

There are reports on the scapula morphology of old squirrels (Emry and Thorington, 1984), Wistar rats (Greene, 1968; Hebel and Stromberg, 1976) and Rattus rattus (Ozkan et al., 1997; Carter et al., 1998). However, there is dearth of information on the comparative scapular morphology and osteometric variables in African tree squirrel (Funisciurus anerythrus), Rattus rattus and Wistar rat. Hence, this study seeks to investigate the differences between an arboreal and a more or less terrestrial species.

\section{MATERIALS AND METHODS}

\section{Animals}

A total of thirty-three animals of three rodents' species [African tree squirrel, Rattus rattus and Wistar rats; 11 animals/rodent species] were used for the study. The African Tree Squirrel and Rattus rattus were captured from their natural habitats while the Wistar rats were purchased from the Experimental Animal House of the University of Ibadan, Ibadan, Nigeria. The animals were healthy with no apparent sign of fracture on their body parts. Each of the animal's life weight (Wistar rat: $128 \pm 0.2 \mathrm{~g}$; Rattus rattus. $132 \pm 0.52 \mathrm{~g}$ and squirrel: $165 \pm$ $1.21 \mathrm{~g}$ ) was taken using weighing balance.

\section{Anaesthesia}

The experimental animals were anaesthetisized using ketamine $(80 \mathrm{mg} / \mathrm{kg}: 10 \mathrm{mg} / \mathrm{kg}$ body weight) and decapitated. Individually, their carcasses were packed in labeled nylon filled with sand and manure and left to decompose over a period of two weeks. Then the carcasses were washed with detergent and rinsed in clean water. The scapulae, both right and left were obtained and air dried.

\section{Measurements}

Common scapular osteometric variables were measured using digital vernier caliper (BruderWerkzeuge ${ }^{\circledR}$, Germany).

The following measurements were taken:

Scapula whole length (SWL): The distance from the highest point of the dorsal margin to the lowest point on the ventral margin border of the scapula.

Scapula spine length (SSL): The distance between the proximal and the distal end of the scapula

Length of acromial process (LAP): The distance between the distal end of the scapular spine and the most distal part of the acromion process

Coracoid process length (CPL): The longest distance of the structure

Scapula width (SW): The widest distance between the scapula cranial and caudal border

Length of the glenoid (LG): The widest distance of the glenoid structure. 
Length of the scapula neck (LSN): The distance between the scapular spine and the lowest projection of the glenoid surface

Scapular neck width (WSN): The widest distance between the cranial and caudal border of the scapula

Diameter of the supra spinous fossa (DSF): The widest distance between the scapular spine and the cranial border of the scapula.
Diameter of the infra spinous fossa (DIF): The widest distance between the scapular spine and the caudal border of the scapula.

\section{Statistical Analysis}

The data obtained was analyzed using one-way analysis of variance (ANOVA) and Turkey was used for multiple comparisons at post hoc between the three rodent species. The results were presented as group mean \pm standard error of mean; while the level of significance was $p<0.05$.

\section{RESULTS}

\section{Gross Description of the Scapula in the Squirrel, Rattus rattus and Wistar rats Squirrel (Funisciurus anerythrus)}

The gross appearance of the scapula of the tree squirrel is shown in figure 1 . The scapula is flat with a semicircular shape (Figure 4). The dorsocranial border presents a curved outline while the caudal border is straight. The caudal border is rather folded to bear a spine that extends to the articular angle. The proximal $1 / 3^{\text {rd }}$ of the scapula is extended beyond the caudal border. The scapula spine acromion expands over the caudal scapula spine. The acromion bears a prominent process, the metachromion, which extends cranially with a slight hook-like curve unlike the supra-hamate process seen in the cat scapula (Pasquini and Spurgeon, 1992). This structure is also observed in Rattus rattus and the Wistar rat but more prominent in Funisciurus anerythrus. Medially, the subscapular fossa bears a characteristic sub scapula spine that slant from the dorsa border to the neck of scapula dividing the supra spinous part of the sub-scapula fossa so that the fossa is pronounced at the infra spinous area in a grove like fashion along the line of the scapula spine. The neck, a slight constriction, joins the ventral border which bears a shallow glenoid cavity. Medial to the glenoid tubercle is a prominent hook-like coracoid process that is oriented caudo-ventrally beyond the articular angle.

\section{Rattus rattus}

The scapula of Rattus rattus is grossly presented in Figure 2. The scapula is flat and almost triangular in shape (Figure 4). The scapula spine extends from the dorsal border to stop at the distal part of the body where the neck begins, so that a thin long acromial process extends from that point beyond the ventral border of the scapula. The caudal border is slightly folded so that a caudal scapula spine or process as seen in the squirrel is not pronounced. On the medial surface, there is no sub-scapula spine on the fossa. However, the sub-scapula fossa is deeper than that observed in the African tree squirrel. The neck is longer and narrower than that of the African tree squirrel. The acromion is not as expanded as noticed in the African tree squirrel but bears a smaller hamate process which is also cranioventrally directed. The long coracoid process is also caudo-ventrally directed as observed in the African tree squirrel. The caudal border is roughly straight and the cranial border at the proximal $1 / 3^{\text {rd }}$ which is also straight then slops into a steep to merge into the narrow neck.

\section{Wistar Rat}

The Wistar rat scapula has a roughly triangular shape (Figure 4) that is similar to that of the Rattus rattus but the cranial border has a curved outline unlike the straight outline at the dorsal part before the slope in the Rattus rattus (Figure 3.) The neck, acromion and the medial 

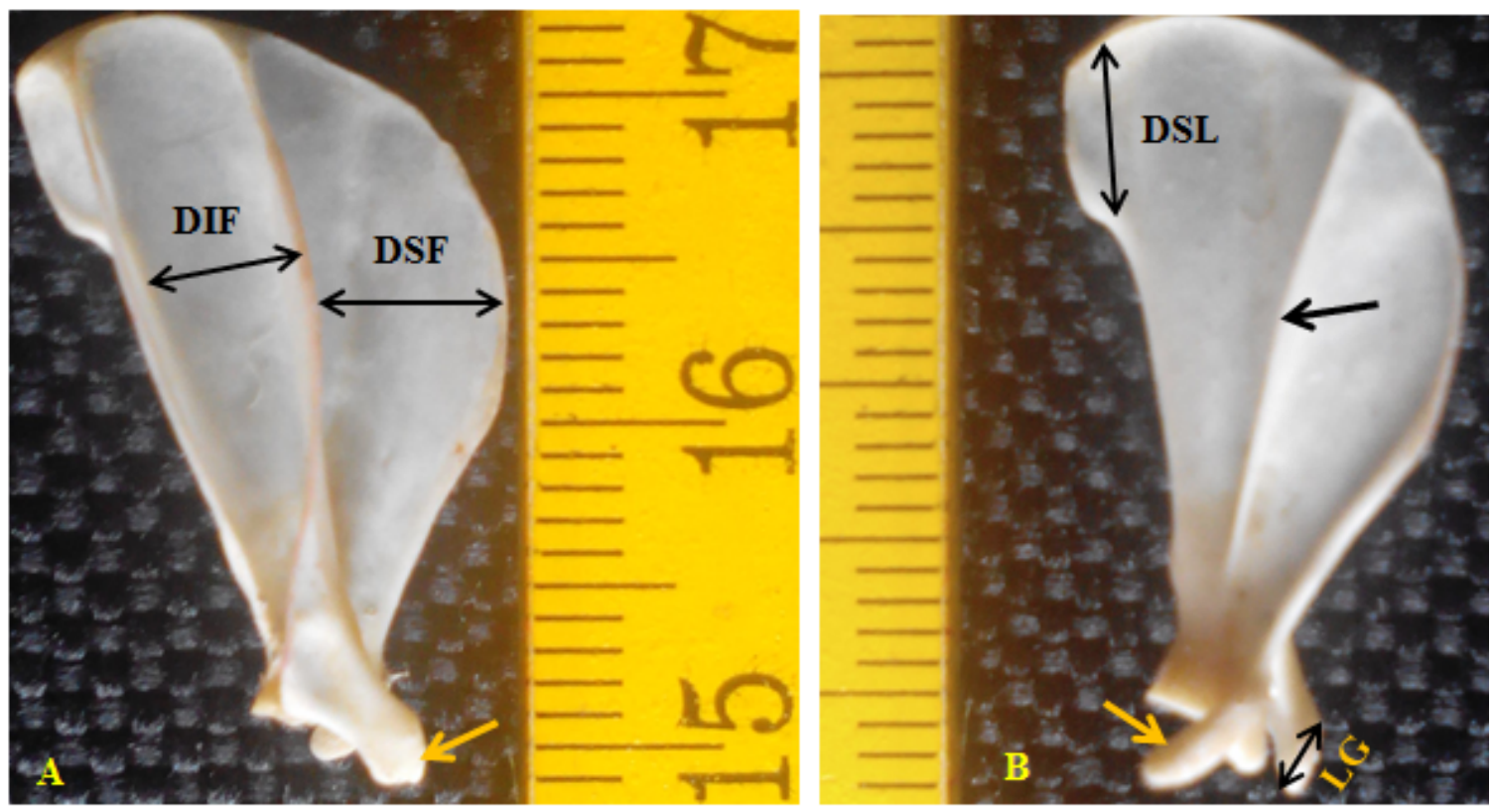

Figure 1. Photographs of the left lateral (A) and medial (B) surfaces of the African Tree Squirrel scapula showing osteometric variables; diameter of the supra-spinous fossa (DSF), diameter of the infra-spinous fossa (DIF), length of glenoid (LG) and the dorso-caudal scapular process length (DSL). This is almost lost in the other two species of rodent. Note that arrow points to the subscapular spine which is absent in Rattus rattus and the Wistar rat, and the yellow arrow points to metacromion (A) and the coracoid process (B)
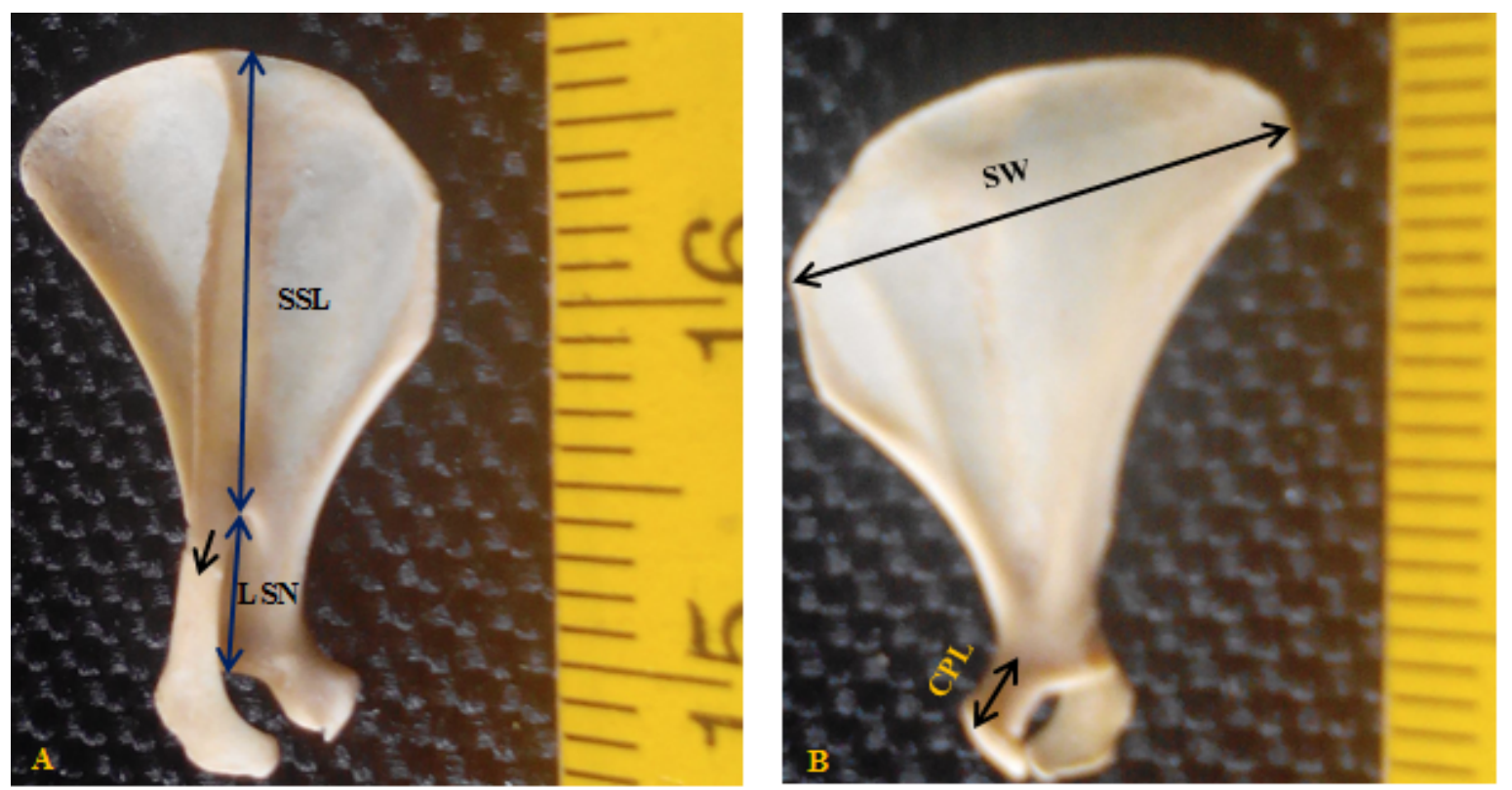

Figure 2. Photographs of the left lateral (A) and the medial (B) surfaces of Rattus rattus scapula with ostemetric variables; scapular neck (LSN), scapular width (SW), and length of the coracoid process (CPL). Black arrow points to the acromion. 

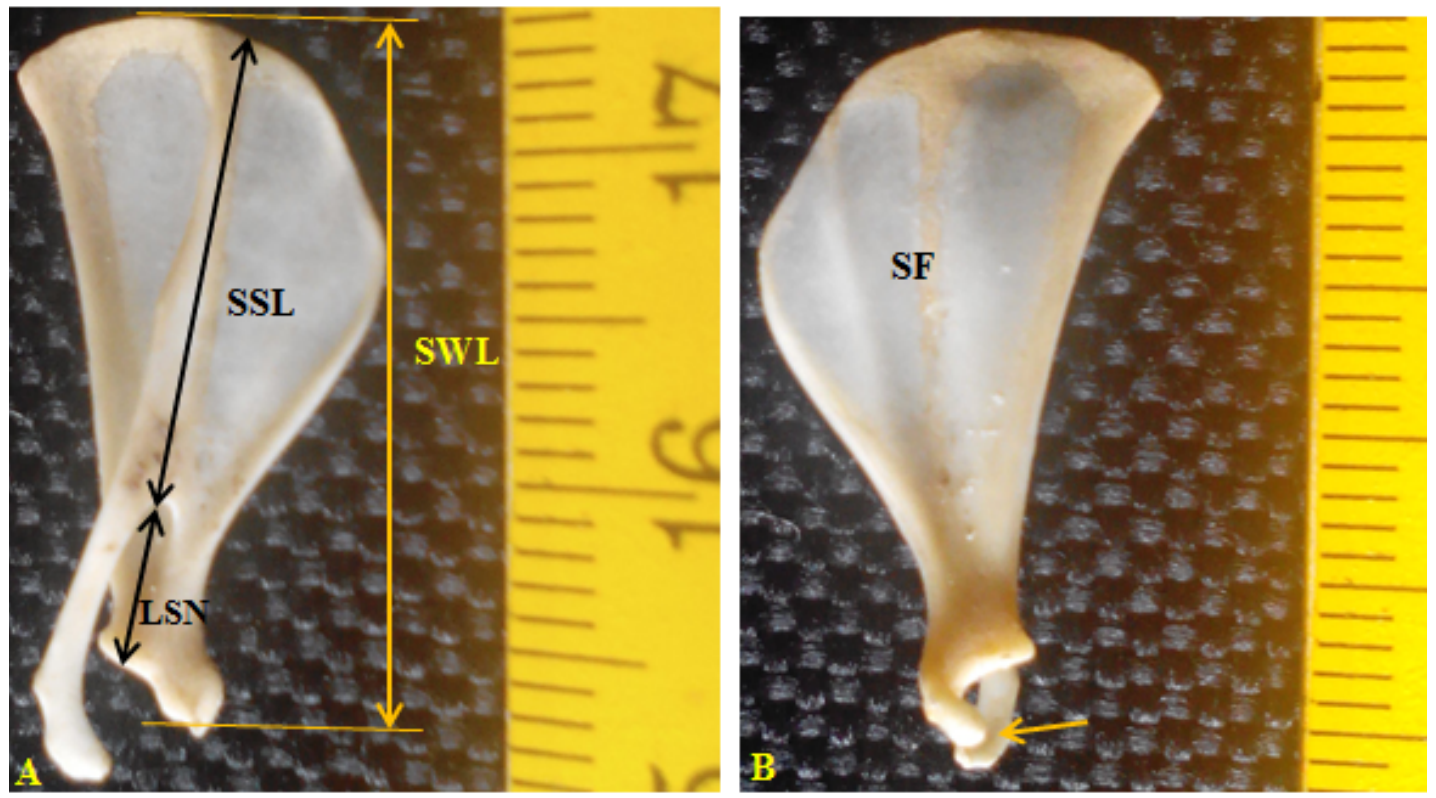

Figure 3. Photographs of the left lateral (A) and the medial (B) surfaces of the Wistar rats' scapula showing some osteometric variables; whole height of the scapula (SWL), length of the scapular spine (SSL) and length of scapular neck (LSN). Note the subscapular fossa (SF) is without spine. Yellow arrow points to the metacromion.

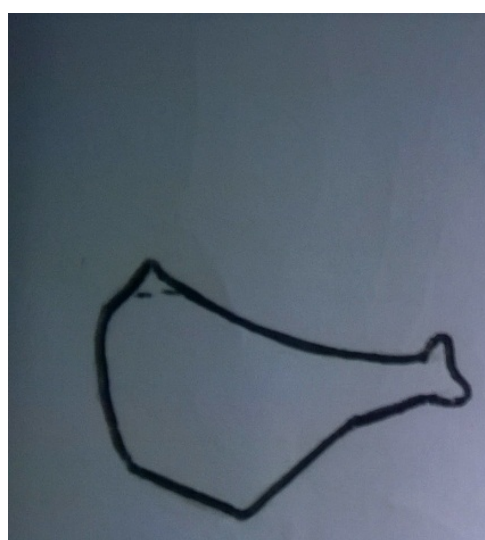

A

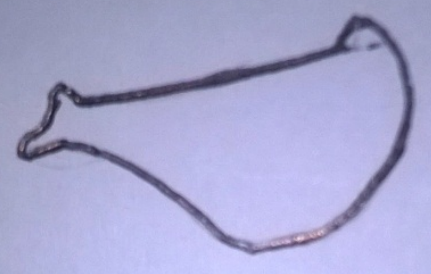

B

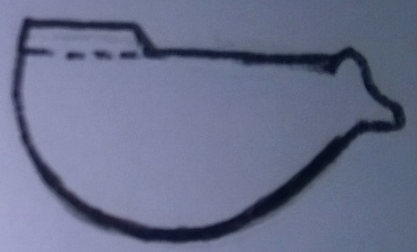

C

Figure 4. Ink traced diagrams illustrating the scapular shapes of the rodents used for this study. A: represents the Rattus rattus scapula with a fan shape; B: stands for the Wistar rat scapula which is roughly triangular and; C: represents African Tree Squirrel (Funisciurus anerythrus), which roughly appears like a semi-circle.

\section{Scapular osteometrics}

Osteometric variables observed on the scapular in the three rodents are presented in Table 1.

\section{SSL (Scapula spine length)}

The SSL values of the right and left scapulae in each of the rodents are not 
significantly different ( $p>0.05)$ within the group. However, the squirrel SSL values increased significantly relative to Wistar and Rattus values.

\section{SW (Scapula width) and LSN (Length of the scapular neck)}

The SW and LSN values of the right and left scapulae are not significantly different $(p>0.05)$ within each group of the rodents investigated. However, between the group of studied rodents, Wistar and squirrel show a markedly decrease SW values in their scapular relative to Rattus values. Similarly, LSN is reduced in rattus and most especially in squirrel when compared to the Wistar rat values.

\section{LG (Length of the glenoid)}

With the exception of the paired scapulae of squirrel, the LG values vary significantly $(p<0.05)$ within the scapulae of the rodents studied. Comparison between the group reveals that the LG of Rattus specifically the left scapula significantly increase $(p<0.05)$ relative to others.

\section{DIF (Diameter of the infra spinous fossa)}

There is no significant difference $(p>0.05)$ in the DIF values within each group of the rodent species. On the other hand, there is marked increase in DIF values of the Rattus compared to others.

SWL (Scapula whole length), LAP (Length of acromial process) SNW (Scapular neck width) DSF (Diameter of the supra spinous fossa) and CPL (Coracoid process length)

The SWL, LAP, SNW, LSN and coracoid process values of the right and left scapulae are not significantly different $(p>0.05)$ between and within each group of the rodents studied.

Table 1. Comparative scapular osteometrics variables in squirrel, Rattus rattus and Wistar rats

\begin{tabular}{|c|c|c|c|c|c|c|c|}
\hline & \multicolumn{2}{|l|}{ WISTAR } & \multicolumn{2}{|l|}{ RATTUS } & \multicolumn{2}{|l|}{ SQUIRREL } & \multirow{2}{*}{$\begin{array}{l}\text { W v } R \text { v } \\
S \\
p \text { value }\end{array}$} \\
\hline & RIGHT & LEFT & RIGHT & LEFT & RIGHT & LEFT & \\
\hline$\overline{\mathbf{S W L}}$ & $\begin{array}{l}23.18 \\
0.21 \\
\end{array}$ & $\begin{array}{ll}23.00 \quad \pm \\
0.21 & \\
\end{array}$ & $\begin{array}{ll}22.56 & \pm \\
0.18 & \\
\end{array}$ & $\begin{array}{ll}22.78 & \pm \\
0.28 & \\
\end{array}$ & $22.60 \pm 0.16$ & $\begin{array}{l}22.80 \\
0.25\end{array}$ & 0.4061 \\
\hline SSL & $\begin{array}{l}15.88 \\
0.17^{b}\end{array}$ & $\begin{array}{ll}15.59 & \pm \\
0.17^{\mathrm{b}} & \\
\end{array}$ & $\begin{array}{l}14.44 \\
0.18^{\mathrm{b}}\end{array}$ & $\begin{array}{ll}14.56^{\mathrm{b}} \quad \pm \\
0.18^{\mathrm{b}}\end{array}$ & $\begin{array}{ll}19.90 & \pm \\
0.18^{\mathrm{a}} & \end{array}$ & $\begin{array}{ll}19.60 & \pm \\
0.16^{\mathrm{a}} & \\
\end{array}$ & 0.0003 \\
\hline LAP & $\begin{array}{l}7.53 \\
0.12\end{array}$ & $\begin{array}{ll}8.12 & \pm \\
0.12 & \end{array}$ & $\begin{array}{ll}8.44 & \pm \\
0.18 & \end{array}$ & $8.44 \pm 0.18$ & $5.70 \pm 0.26$ & $5.33 \pm 0.17$ & 0.4854 \\
\hline CPL & $\begin{array}{l}3.35 \\
0.02\end{array}$ & $\begin{array}{l}3.88 \\
0.08\end{array}$ & $3.2 \pm 0.15$ & $3.89 \pm 0.11$ & $3.60 \pm 0.16$ & $3.67 \pm 0.17$ & 0.1500 \\
\hline SW & $\begin{array}{l}11.29 \\
0.11^{c}\end{array}$ & $\begin{array}{ll}11.53 & \pm \\
0.12^{\mathrm{c}} & \\
\end{array}$ & $\begin{array}{l}16.67 \\
0.17^{a}\end{array}$ & $\begin{array}{l}15.67 \\
0.41^{a}\end{array}$ & $\begin{array}{ll}13.60 & \pm \\
0.48^{\mathrm{b}} & \end{array}$ & $\begin{array}{l}13.89 \\
0.70^{\mathrm{b}}\end{array}$ & 0.0001 \\
\hline LG & $\begin{array}{l}3.65 \\
0.11^{\mathrm{b}}\end{array}$ & $\begin{array}{ll}2.88 & \pm \\
0.08^{\mathrm{c}} & \end{array}$ & $\begin{array}{l}3.11 \\
0.20^{\mathrm{b}}\end{array}$ & $\begin{array}{ll}4.66 & \pm \\
0.16^{\mathrm{a}} & \end{array}$ & $3.30 \pm 0.15^{b}$ & $\begin{array}{l}3.22 \\
0.22^{b}\end{array}$ & 0.0001 \\
\hline SNW & $\begin{array}{l}3.88 \\
0.08\end{array}$ & $\begin{array}{l}3.82 \\
0.09\end{array}$ & $\begin{array}{l}3.78 \\
0.15\end{array}$ & $3.89 \pm 0.11$ & $3.90 \pm 0.10$ & $4.22 \pm 0.15$ & 0.1540 \\
\hline DSF & $\begin{array}{l}6.05 \\
0.12\end{array}$ & $\begin{array}{l}5.47 \\
0.23\end{array}$ & $\begin{array}{l}6.00 \\
0.29\end{array}$ & $6.00 \pm 0.28$ & $5.50 \pm 0.22$ & $5.67 \pm 0.17$ & 0.1148 \\
\hline DIF & $\begin{array}{l}4.88 \\
0.15^{b}\end{array}$ & $\begin{array}{ll}5.59 & \pm \\
0.24^{\mathrm{b}} & \\
\end{array}$ & $7.440 .18^{a}$ & $7.110 .35^{\mathrm{a}}$ & $4.20 \pm 0.13^{b}$ & $4.330 .166^{b}$ & 0.0001 \\
\hline LSN & $\begin{array}{l}5.47 \\
0.12^{\mathrm{a}}\end{array}$ & $\begin{array}{ll}5.71 & \pm \\
0.11^{\mathrm{a}} & \end{array}$ & $\begin{array}{l}5.22 \\
0.15^{b}\end{array}$ & $\begin{array}{l}4.67 \\
0.17^{b}\end{array}$ & $2.90 \pm 0.23^{c}$ & $\begin{array}{l}3.20 \\
0.20^{c}\end{array}$ & 0.0001 \\
\hline
\end{tabular}


Values with different superscripts are significantly different VAR (Variable), SWL (Scapula whole length), SSL (Scapula spine length), LAP (Length of acromial process), CPL (Coracoid process length), SW (Scapula width), LG (Length of the glenoid), SNW (Scapular neck width), DSF (Diameter of the supra spinous fossa), DIF (Diameter of the infra spinous fossa), LSN (Length of the scapular neck)

\section{DISCUSSION}

This study has demonstrated that scapulae bone in the three rodent species (Funisciurus anerythrus, Rattus Rattus and Wistar rats) investigated show gross morphological differences and diverging osteometric variables. The scapular bones in all the rodents are flat and assumed different shapes; semicircular in squirrel and roughly triangular in both Rattus rattus and Wistar rats. Also, there is an exclusive presence of subscapular spine in squirrel scapula and a more pronounced metachromion process relative to other rodents. Few osteometric variables (SSL, CPL, SW, LG, DIF and LSN) markedly differed between the three species. The findings on the gross morphological differences and divergent osteometric variables are similar to earlier reports on Wistar rats (Greene, 1968; Hebel and Stromberg, 1976), guinea pigs, rabbits and rats (Ozkan et al., 1997) and squirrel (Emry and Thorington, 1984).

Generally, the shape of the scapula in mammalian species is triangular (Dyce et al., 2002) and the morpho-physiological relevance of such is to accommodate and attach several muscles that assist in holding the weight of the trunk (Preuschoft et al., 2010; Nyakatura and Fischer, 2011; Kawashima et al., 2015). Therefore, the observed triangular shape of scapular in the Rattus rattus and Wistar rats is in consonance with the assertion made by Dyce et al. (2002). However, the semicircular appearance of the squirrel scapular contrasted the statement. The possible reasons for this difference has been posited to include variation in intrinsic genetic factors associated with bone shape, epigenetic factors such as variance in muscle attachments that affect bone shape and variance of in utero neuromuscular activity that co-ordinate these epigenetic effects (Carter et al., 1998; Zelditch et al., 2004b; Nowlan and Prendergast, 2005). In addition, the magnitude and direction of the forces exerted by the muscles that have their attachment to scapular is culpable in the variation in the scapular shape (Hildebrand, 1985; Szalay and Sargis, 2001; Sargis, 2002).

The observed acromion and metacromion (hamate) processes in the scapular of all the rodent species investigated is similar to the previous reports on the presence of acromion and metacromion (hamate) processes in Wistar rats (Greene, 1968; Hebel and Stromberg, 1976), in guinea pigs, rabbits and rats (Ozkan et al., 1997). The hamate process has been consistently described typical of the scapula of carnivores, while a suprahamate process is present only in the cat (Dyce et al., 2002). It is important to mention that none of the rodents bears suprahamate process.

The presence of subscapular spine in the scapular of Funisciurus anerythrus squirrel further corroborates the documented taxonomic peculiarity of scuiridae family members that ranges from small chipmunks to large marmots and from ground squirrels, to tree squirrels, to flying squirrels (Emry and Thorington, 1984).

Five osteometric variables (scapular spine length, scapula width, length of the glenoid, diameter of the infra spinous fossa and length of the scapular neck) markedly differ out of the 10 variables investigated in the rodents. The marked increased scapular spine length as well as the reduced scapular neck length observed in the squirrel further substantiates the gross features earlier described on the costal surface and ventral border respectively. Similarly, the increased infraspinatus fossa diameter and the 
decreased acromial process length observed in the squirrel and Rattus rattus respectively validate the previously described gross features in this study.
In conclusion, the scapula of the Funisciurus anerythrus out of the three rodents investigated bears a striking feature such as the ending of scapular spine in a prominent acromion that substantiate its classification as climbing rodent.

Conflict of interest: The authors declare that there is no conflict of interest regarding the publication of this article.

\section{REFERENCES}

1. Aplin KP, Suzuki H, Chinen AA, Chesser RT, Ten Have J, Donnellan S.C, Austin J, Frost A, Gonzale JP, Herbreteau V, Catzeflis F, Soubriere J, Yin-Ping Fang Y.-P, Robins J, MatisooSmith E, Bastos ADS, Maryanto I, Sinaga MH, Denys C, Ronald A, Van Den Bussche RA, Conroy C, Rowe K, Cooper A, 2011. Multiple geographic origins of commensalism and complex dispersal history of black rats PloS One, 6 (2011) p. e26357.

2. Barnett SA, 2001. The Story of Rats: Their Impact on Us, and Our Impact on Them Allen and Unwin, Crows Nest, NSW, Australia.

3. Carter DR, Mikic B Padian K, 1998. Epigenetic mechanical factors in the evolution of long bone epiphyses. Zoological Journal of Linnean Society. 123: 163-178.

4. Clause BT, 1998. The Wistar Institute Archieves. Rats (Not Mice) and History, Mendel Newsletter. $\quad$ Retrieved $\quad$ on $25^{\text {th }} \quad$ Wednesday, 2017 from http://www.amphilsoc.org/library/mendel/1998.htm.

5. Dyce KM, Sack WO, Wensing CJG, 2002. Veterinary Anatomy, 3rd edition, W.B. Saunders Company, Philadelphia, pp 76-81.

6. Emry RJ Thorington JR, 1984. The tree squirrel Sciurus (Sciuridae, Rodentia) as a living fossil. Pp. 23-31 (Eldredge N Stanley SM eds.). Springer-Verlag, New York, 291pp.

7. Greene CE, 1968. The anatomy of the rat: Transactions of the American Philosophical Society. New Series. Hafner Publishing Company, New York, London.

8. Hebel R Stromberg M, 1976. Anatomy of the laboratory rat. Williams and Wilkins Company, Baltimore, MD.

9. Hildebrand $M, 1985$. Digging in quadrupeds. In: Hildebrand M, Bramble DM, Liem KL, Wake DB (Eds.), Functional Vertebrate Morphology. Harvard University Press, Massachusetts, pp. 89-109.

10. Hoffman RS, Andrews CG, Hildebrand M, 1985. Digging in quadrupeds. In: Hildebrand $M$, Bramble DM, Liem KL, Wake DB. (Eds.), Functional Vertebrate Morphology. Harvard University Press, Massachusetts, pp. 89-109.

11. Innes, 2005a. Ship rat. Pages 187 - 203 in C. A. King, ed. The handbook of New Zealand mammals. 2nd ed. Oxford University Press, Oxford.

12. Kawashima T, Thorington RW, Bohaska PW, Chen Y, Sato F, 2015. Anatomy of Shoulder Girdle Muscle Modifications and Walking Adaptation in the Scaly Chinese Pangolin (Manis Pentadactyla Pentadactyla: Pholidota) Compared with the Partially Osteoderm-Clad Armadillos (Dasypodidae). The Anatomical Record. 298 (7): 1217-1236.

13. Leamy L Atchley WR, 1984. Morphometric integration in the rat (Rattus sp.) scapula. Journal of Zoology. 202 (1): 43-56

14. Nowlan NC Prendergast PJ, 2005. Evolution of mechanoregulation of bone growth will lead to non-optimal bone phenotypes. Journal of Theoretical Biology. 235: 408-418.

15. Nyakatura JA, Fischer MS, 2011. Functional morphology of the muscular sling at the pectoral girdle in tree sloths: convergent morphological solutions to new functional demands. Journal of Anatomy. 219 (3): 360-374. 
16. Özkan ZE Dinç G Aydin A, 1997. Tavsan (Oryctolagus cuniculus) kobay (Cavia porcellus) ve ratlarda (Rattus norvegicus), scapula, clavicula, skeleton brachii ve skeleton antebrachii'nin karsılastırmalı gross anatomisi üzerinde incelemeler. Fırat Ün Sag Bil Derg. 11: 171-175.

17. Preuschoft H, Hohn B, Scherf H, Schmidt M, Krause C, Witzel U, 2010). Functional Analysis of the Primate Shoulder. International Journal of Primatology. 31 (2): 301-320.

18. Rupert JE, Cordero SE, Moriera-Soto A, Rodriguez HB, VandeBerg JL, Butcher MT, 2014. Myosin heavy chain (MHC) isoform expression in the prehensile tails of didelphid marsupials: functional differences between arboreal and terrestrial opossums. The Anatomical Record. 297: 1364-1376.

19. Sargis EJ, 2002. Functional morphology of the forelimb of tupaiids (Mammalia, Scandentia) and its phylogenetic implications. Journal of Morphology. 253: 10-42.

20. Shiels AB, Pitt WC, Sugihara RT, Witmer GW, 2014. Biology and Impacts of Pacific Island Invasive Species. Rattus rattus, the Black Rat (Rodentia: Muridae). Pacific Science. 68 (2):145184.

21. Shiels $A B, 2010$. Ecology and impacts of introduced rodents (Rattus spp. and Mus musculus) in the Hawaiian Islands. Ph.D. diss., University of Hawai 'i at Mänoa, Honolulu.

22. Szalay FS, Sargis EJ, 2001. Model-based analysis of postcranial osteology of marsupials from the Palaeocene of Itabora (Brazil) and the phylogenetic sand biogeography of Metatheria. Geodiversitas. 23:139-302.

23. Thorington RW Darrow K, 2000. Anatomy of the squirrel wrist, bones, ligaments and muscles. Journal of Morphology. 246:85-102.

24. Thorington RW, Darrow K Betts DK, 1997. Comparative mycology of the forelimb of squirrels (Sciuridae). Journal of Morphology. 234:155-182.

25. Valasek P, Theis S, Krejci E, Grim M, Maina F, Shwartz Y, Otto A, Huang R, Patel K, 2010. Somitic origin of the medial border of the mammalian scapula and its homology to the avian scapula blade. Journal of Anatomy. 216 (4): 482-8.

26. Young N (2006) Function, ontogeny and canalization of shape variance in the primate scapula. J. Anat, 209: 623-636.

27. Zelditch ML, Swiderski DL, Sheets HD Fink WL, 2004b. Geometric Morphometrics for Biologists: a Primer. New York: Academic Press. 